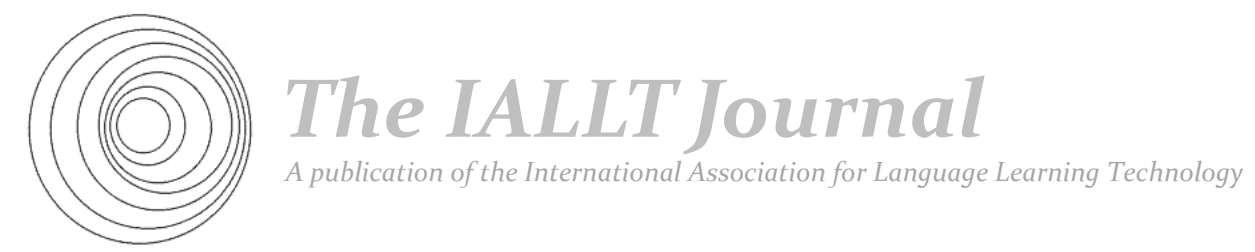

\title{
Web 2.0 TeChNOLOgy MeEts Mobile ASSISTED LANGUAGE LEARNING
}

\author{
Min Jung Jee \\ University of Texas at Austin
}

\begin{abstract}
This paper is intended to provide a brief introduction to a wide variety of emerging Web 2.0 and mobile technologies that can be used to great effect in foreign and second language teaching. Specifically, the unique potential and anticipated growth of mobile technologies for language production and consumption are discussed as an ideal opportunity to increase the authenticity, engagement and efficiency, and overall effectiveness of language learning within and beyond the classroom. A number of representative mobile Web 2.0 technologies will be examined and their applications to language pedagogy will be elucidated in conjunction with relevant paradigms of second language acquisition theory and instructional praxis. Implications for future innovation and opportunities for additional research will be discussed.
\end{abstract}

\section{INTRODUCTION}

It is common to observe students on campus who are texting their friends using PDAs, cell phones or iPhones, or searching and working on the internet using net books or small laptops. They are often busy with these mobile devices while they wait for class to begin. Even during a class, their fingers, eyes and sometimes ears are occupied by these daily technological routines. These small devices become a link to their peers, and texting, watching or listening via these small devices becomes a fundamental part of their daily language consumption and production. So, these interactions with handy devices become routine in their lives. It is 
predictable that in the near future, with the development of cheaper and more convenient small devices, everybody might make these routines natural. Thus, the intention of the paper is to investigate how these small devices with social networking capabilities can provide pedagogically useful functions in education, especially foreign language instruction.

As mobile technology develops, it affords second or foreign language learners and teachers ever greater opportunity to practice the target language "anywhere and anytime (Geddes, 2004).” Moreover, with less expensive devices, it is becoming more and more common to use technology in learning and teaching contexts. With its portability, mobile technology expands learning and teaching opportunities for second and foreign language learners and teachers. Moreover, with user created content, which enhances users' participation, Web 2.0 technology provides new kinds of learning and teaching with technology in second and foreign language instruction. In addition, because the basic concept of Web 2.0 is sharing information and collaboration (see the definition in the next section), it makes it easier for learners to connect not only to other learners, but also to native speakers of the target language around the world. Most of all, the use of these technologies addresses many of the major challenges of Second Language Acquisition (SLA), such as comprehensible input or “i+1" (Krashen, 1985), the interaction hypothesis (Long, 1983, 1996), corrective/facilitative feedback (Gass, 1997; Long, Inagaki, \& Ortega, 1998), and learner autonomy (Benson, 2001).

It is both timely and appropriate to investigate how these technologies can be implemented in foreign language instruction. Even though empirical research using these technologies is still scarce, it is worthwhile to see what opportunities are available and make suggestions for future use and research. Thus, this paper intends to outline theoretical and praxiological foundations in MALL and CALL and suggest pedagogical templates for the use of Web 2.0 and mobile devices in foreign language instruction. Specifically, this paper intends to provide a basic framework for how Web 2.0 technology can be used in second or foreign language learning and teaching with mobile devices, and illustrate sample activities of MALL as they apply to pedagogical paradigms of second language acquisition. This paper concludes with suggestions for future research or future use, pedagogical benefits and limitations.

\section{MALL \& WEB 2.0}

In this section, I will provide brief definitions and basic explanations in order to provide background information on Mobile Assisted Language learning (MALL) and Web 2.0 and for background knowledge of key terms and theories of this paper. First of all, mobile assisted language learning or MALL can be called m-learning or Mobilearn (Chinnery, 2005). MALL can be any type of language learning using 
portable devices, such as mobile phones, MP3/MP4 players, PDAs, palmtop

computers, portable radios and DVD players, and electronic dictionaries (KukulskaHulme \& Shield, 2008). Trifanova et al. (2003) defined mobile devices as “... any device that is small, autonomous and unobtrusive enough to accompany us in every moment (cited in Kukulska-Hulme \& Shield, 2008).” Thus, MALL uses handy devices and they should be available "anywhere, anytime (Geddes, 2004)." Another important concept is Web 2.0 technology. Web 2.0 "is commonly associated with web applications which facilitate interactive information sharing, interoperability, user-centered design and collaboration in the World Wide Web (Wikipedia)." Content is created and shared by the users. Web 2.0 technology has free or low cost access and promotes socializing without time and place limitation. Common examples of Web 2.0 are blogs, wikis, and social-networking web-sites such as Facebook or Twitter. They allow users to interact with others or collaborate with others "anywhere and anytime" if they have internet access.

In terms of the theoretical orientation of MALL and Web 2.0, I will review eliteracy, input, interaction, and feedback in Second Language Acquisition (SLA), and autonomy in language learning. As technology has changed people's reading and writing patterns in the past decade, it has developed a new type of literacy, known as "e-literacy." E-literacy refers to "the ability to find, select, organize and make use of information, as well as to read and write in the new medium" (Warschauer \& Shetzer, 2000, p. 172). It can be divided into information literacy, digital literacy, and media literacy. E-literacy is an important concept in education, and is particularly important in SLA because using technology is a very common way of using language among native speakers. For example, more and more native speakers of English in the U.S. read newspapers online, find information by Googleing, and listen to music or watch movies after downloading them from websites. This is a common routine not only for native speakers of English, but also for many native speakers of other languages who live in countries with advanced technology. Thus, it is important to allow learners to learn e-literacy as a tool for better learning a foreign or second language.

The use of mobile devices and Web 2.0 tools are supported by major SLA theoretical paradigms such as Krashen's (1985) input hypothesis, Long's (1983, 1996) interaction hypothesis and models of corrective/facilitative feedback (Gass, 1997; Long, Inagaki, \& Ortega, 1998). Krashen (1985) proposed the concept of comprehensible input, which refers to the idea that is a little beyond one's current target language level $(i+1)$ is the necessary and sufficient condition for target or second language (L2) development, and that learners should be exposed to an " $\mathrm{i}+1$ " level of input only.

While Long's (1983, 1996) interaction hypothesis also emphasizes the importance of input, it additionally focuses on output. According to Long, negotiation of meaning through interaction facilitates L2 acquisition because it 
connects input and output through selective attention. Thus, negotiation is important

to give learners opportunities to get input and to practice output. In terms of feedback, there are two types of feedback, positive and negative. They both play critical, though different, roles in L2 acquisition. Positive feedback confirms learners' language production as correct or acceptable so that the learner can strengthen his or her L2. Negative feedback informs a learner that certain forms are not acceptable so that the learner can reconstruct his or her interlanguage. Given this, MALL and Web 2.0 tools are good ways of facilitating L 2 acquisition in terms of input, interaction and feedback.

Portability and easy access to Web 2.0 tools such as blogs or wikis through mobile devices enable learners to be exposed to L2 anytime and anywhere. The input could be from native speakers, which enhances the L2 learner's authentic use of the target language. It could also be from other L2 learners, which provides more opportunities to negotiate meaning. Moreover, by nature, Web 2.0 tools promote social networking or social relationships on the net. That means that with careful guidance and design by expert pedagogues, Web 2.0 technology may have the potential to enhance meaningful interaction, not only between Non-native speakerand Non-native speaker (NNS-NNS) but also between Native-speaker and Nonnative speaker (NS-NNS). Finally, through social interaction, learners may give and receive feedback, which is also meaningful for learners. Thus, mobile devices and Web 2.0 provide more chances to interact by giving and receiving feedback as input and output for foreign language learners than previously developed technology.

Learner autonomy is also an important component of L2 learning (Benson, 2001). Autonomy means "the ability to take charge of one's own learning (Holec, 1979)." Inherent in this is the need of the learner to determine the learning objectives, define the content and progression of learning, and select methods and techniques to be used (Benson, 2001). As a result, autonomous learners are "flexible, persistent and responsible, venturesome and creative, independent and self-sufficient, and curious, open and motivated (Candy, 1991, pp. 459-66).” In fact, learner autonomy should be an ultimate goal of all parts of education because it enables learners to continue their learning independently.

Benson (2001) suggested six ways of fostering autonomy, and one of these emphasizes a technology-based approach. By teaching learners how to use technology independently, learners may have more chances to become autonomous users than traditional classroom learners. They can find study materials by searching the web and independently determine how to study the content. Thus, mobile devices and Web 2.0 technology can enhance learners' autonomy if learners are properly taught and well practiced. Once learners are taught how to use basic functions of small mobile devices to operate Web 2.0 technology with guidance, they can find essential learning materials and decide how to study these. Moreover, 
they can select which programs or tools are necessary to study their desired topics. They can then study independently anytime and anywhere.

\section{REPRESENTATIVE TECHNOLOGIES}

This section will review how to use MALL and Web 2.0 tools as a part of classroom instruction for both teachers and learners who are new to this technology. In terms of mobile devices, it does not matter which particular device is used, as long as it has internet access with the ability to enter text and SMS or MMS technology to upload what learners have written or photographed while they were moving. Thus, the basic requirement for MALL with Web 2.0 in foreign language instruction is to have access to the internet and to be able to upload and download messages or pictures/videos to interact with others.

\section{Blogs}

A blog is an "online journal that an individual can continuously update with his or her own words, ideas, and thoughts through software that enables one to easily do so (Campbell, 2003).” With easy and free access, blogs have some benefits. Most of all, they require no knowledge of HTML or FTP and are easy to create and manage. They have a minimal level of viruses and spam and are easily linked and crosslinked to create larger on-line communities. Pedagogically, they promote interaction and collaboration by allowing users to give and receive comments. Furthermore, they have the potential of reaching readers beyond classmates because anyone around the world can read a learner's postings.

Moreover, blogs can be used as online personal journals and electronic portfolios. They can be used as a new assessment tool in the classroom because by their nature, blogs keep recording postings by learners, and teachers can check how much the postings have improved in terms of content and grammar. In addition, students feel responsibility for their writing because they are writing for real audiences (Godwin-Jones, 2003; Ducate \& Lomicka, 2005). So, learners might be more careful in terms of selecting formal grammar or writing styles in their postings.

Using PDAs, iPhones or handheld small laptops (or netbooks or tablet PCs), learners can have easy access to their blogs and check other people's feedback whenever they want. For example, when learners go on a field trip or visit a target language country, they can leave messages or thoughts in their blogs and other classmates; even public audiences can give them feedback on their content as well as their writing style and/or grammar. Finally, learners can use their blogs as book reviews or writing portfolios in a writing class (for more tips on using blogs, see Jee, 2008; Murray \& Hourigan, 2006; Ducate \& Lomicka, 2005; Ward, 2004; Campbell, 2003). 
The above examples describe traditional reading-writing based blog use, but there are other forms of blogging such as Audioblogging, Moblogging, Vlogging, and synchronous blogging, (i.e., Twitter).

\section{Audio Blogging}

Audio blogging is audio plus blogging, so instead of reading and writing, learners can leave voice messages in their blogs and others can listen and leave comments via their voices. Listening-speaking is a more appropriate form than reading-writing in MALL, because listening-speaking is easier and handier while learners are walking or doing something else. Using a voice recorder in their mobile devices, learners can upload their voice-comments, download others' comments, and upload their feedback again.

\section{Moblogging}

Moblogging is "a form of blogging in which the user publishes blog entries directly to the web from a mobile phone or other mobile device (Wikipedia)." Given that, it is the best type of blogging for MALL. Using Moblogging, learners can upload pictures or video clips that were taken by a mobile phone camera. So, learners can take pictures or make videos while they are walking on a street or visiting a new place and upload them in their blogs. Moblogging only needs a mobile device with a camera and SMS or MMS technology. Therefore, it can be best used as a personal diary or travel log when learners travel to the target language country. Moreover, since it not only provides text but also multimedia input, such as listening and watching the contents, Moblogging enhances authenticity.

\section{Vlogging}

Vlogging or Video blogging is "a form of blogging for which the medium is video" and it "takes advantage of web syndication to allow for the distribution of video over the Internet using either the RSS or Atom syndication formats, for automatic aggregation and playback on mobile devices and personal computers (Wikipedia)." Qik is a good example of Vlogging. It allows users to use a wide variety of phones with data plans to stream video via their built-in camera (Wikipedia). Thus, as a host or administer of his or her own blog site, a user can create content with the built-in digital camera in their mobile phone and upload the content to his or her blog, even on the move. In foreign language classes, learners, as a team, can create a short movie or make a video clip to practice conversation and upload their recordings. After watching other teams' videos, they can give and receive feedback. It does not require any expensive and heavy equipment to create a video clip and the blog is easy to manage. 


\section{Synchronous Blogging}

Synchronous blogging is best explained by the example of Twitter. Twitter is "a free social networking and micro-blogging service that enables its users to send and read messages known as tweets (Wikipedia).” Basically, Twitter is a text-based SMS, sending and receiving short messages via the Twitter website. The main feature of Twitter is that users can exchange messages with their intimate friends immediately and synchronously without any cost and without any technical knowledge. In a foreign language class, learners can make friends with either native speakers or other L2 learners and keep in touch with them. Even though it allows only short messages (maximum of 140 characters), if learners keep using the target language via their iPhones or cell phones with texting, Twitter could be an extra credit option to develop their target language. Continuous input and output in an anxiety-reduced environment is one of the key elements for enhancing one's target language.

Thus, with easy, cheap and fast access to other learners, the use of mobile devices for blogging expands traditional uses of blogs such as limitless contact with each other even while 'on the go' and regardless of time and place (for free blog web sites, see endnote 15). However, to use these new types of blogging technologies, such as vlogging and Twitter, 3G or 4G capable phones are often needed.

\section{Wikis}

Since the purpose of a wiki is to become a shared repository of knowledge over time (Godwin-Jones, 2003), it is a very good tool for collaboration or collaborative writing in a foreign language classroom (for more information, see Kessler, 2009). When it is used in a group project, a reader can observe how group members' thoughts and ideas change over a certain period of time. Moreover, since anyone in a team can edit and add to the contents, the flow of thoughts can be traced. In addition, like other Web 2.0 tools, a wiki does not require any technical knowledge and is easy to create and manage. Thus, with simple typing and uploading /downloading technology, learners can participate in a group project using small laptops or PDAs at the time and place of their discretion.

In this way, learners can get feedback almost immediately; the wiki enhances motivation and learners' responsibility in their writing in terms of style and the quality of content. The interaction itself becomes input and output for the learners. Furthermore, since it keeps recording the learners' writings, it can be used as a portfolio of a group project that teachers can employ as an assessment tool throughout the course. As a formative assessment tool, not only can learners get feedback from the teacher, but the teacher can also get feedback from the learners on what the class has achieved so far. Thus, if a wiki is used as a formative assessment tool, it gives an opportunity for teachers to adjust the process or curriculum if the 
learners have problems in achieving the class objectives during a certain period of time. For the learners, it provides an opportunity to check their progress and to modify their study habits throughout the semester. (For features and selection criteria of educational Wikis, see Schwartz, Clark, Cossarin, \& Rudolph, 2004).

\section{Facebook \& Social Networking}

Facebook (http://www.facebook.com/) is a free-to-access social networking website. Thus, it is a user-friendly, informal way of interaction among users. However, it also has the potential to be used in foreign language education via mobile devices. Facebook has many functions, such as sending messages to individuals or to groups. It also allows users to use asynchronous computer-mediated communications (ACMC) such as awiki and blogs, or synchronous computer-mediated communication (SCMC), like online chat. Thus, it can be used as a forum and discussion thread or as an online discussion. The friendly, fun environment of Facebook can help to reduce foreign language learner anxiety, especially in early stages of acquisition and among young learners. With SCMC, learners can communicate informally with their classmates in different places, or they can 'chat' with native speakers that they meet on Facebook, itself. Using PDAs or small laptops, learners can meet anywhere and anytime and interact with each other.

\section{Flickr}

Another promising Web 2.0 technology for language learning is Flickr (http://www.flickr.com). Flickr is a free online photo and video management site that is part of Yahoo. With a Yahoo account, anyone can join Flickr. Users can upload their photos from computers or camera phones by sending an email. It is very like Moblogging and Vlogging, but it has many more functions in terms of editing and organizing. Users can create their own photo books and DVDs with text-based annotations, and share their photos with people around the world. This might be especially useful for early stage foreign language learners.

Learners can start by writing a personal diary with photos; or annotating individual photos. In a group project or at more advanced stages, learners could also create a photo story/narrative. In content-based instruction, learners could use Flickr photos to enhance authenticity of presentations, reports and other creative endeavors. Since learners can share their photos and stories, they can also get feedback, not only from each other, but also from people around the world. Such authentic input and output with feedback from real audiences is critical for language development and the context-rich photo environment provides an ideal substrate for greater retention of learning in memory. Moreover, since it uses visual cues, it might be better for long-term memory. (See the following endnote to learn how to start a Flickr project). 


\section{Google Maps: Personal Maps}

Another potential Web 2.0 technology for foreign language learning is Google Maps (http://maps.google.com/). As a part of Google, users can create their own personal maps including photos, videos and audio via 'My Map.' A number of substantive learning and practice activities can be developed around directions and descriptions wherein learners create and showcase their own maps. Additionally, Google Maps can be used in content-based instruction. For example, in a foreign language literature class, learners can create a map of an author's life with annotations, photos and timelines. With some additional research, learners could even create a map of the settings and storyline for a particular novel. Similarly, in a science content class, learners can create a map illustrating animals' habitats, distributions or migrations with appropriate annotations, descriptions and multimedia. In a music class, learners could create a map following the life and career of a particular musician or even a map for the distribution of a particular musical genre during a particular time period; adding appropriate language use and practice activities to accompany this creative and intellectually engaging project.

What is more, many of these activities can take advantage of geo-tagging technologies available in many of today's mobile devices in order to embellish/enrich their self-created maps with actual travel and visits to the neighborhoods, cities and locations that they profile in their My Maps projects. The distinct advantage of Google Maps is the rich and authentic context it provides to the learning activities and language use; not only can learners associate their language learning with particular tasks, but, via Google Maps, specific and real locations as well. All learners need to do to gets started is go to Google Maps and draw a map based on their research. Google Maps requires only a small laptop or any mobile device with internet access, texting function (optional) and mouse.

In this paper thus far, I have introduced some of the Web 2.0 tools that can be combined with mobile devices in a foreign language learning and teaching context. Web 2.0 tools themselves are easy to use and manage, but with mobile devices, they can be readily used in foreign language classrooms. Given that technology for mobile devices and networking technology will continue to develop rapidly, the opportunities to use mobile devices and Web 2.0 technologies in foreign language instruction will continue to grow.

\section{Pedagogical Recommendations}

In this section, I will present some of pedagogical benefits of these tools in foreign language instruction, especially in improving learners' reading, writing, speaking, and listening skills. As stated above, input, interaction and feedback are the three primary benefits of these technologies. In addition, these technologies facilitate greater authenticity, reduced foreign language anxiety (Horwitz, Horwitz, \& Cope, 
1986) while increasing motivation, opportunities for learner-centered activities, enhanced ownership and personal responsibility among learners, greater flexibility and new mechanisms for meaningful interaction, combining "flow (Csikszentmihalyi, 1991)" with fun, and intertwining multimodal input and output.

Since these technologies offer the opportunity for learners to get input, interaction and feedback from live native speakers, these technologies can increase the authenticity of language use and the interlocutors themselves. Indeed, these technologies are an excellent means of providing authenticity because interaction via such small devices, and the multimodality (reading, writing, speaking and listening) they offer, are exactly how native speakers interact with each other. In addition, since many learners can have unlimited access to Web 2.0 technologies via their handheld devices, they may feel more comfortable than in a traditional classroom environment. And, with greater comfort and the opportunity to pursue their own goals for language learning with greater autonomy will likely increase these learners' motivation and investment in the language acquisition process.

These factors lead to a learning "flow (Csikszentmihalyi, 1991)" adding intrinsic motivation to the learning process and allowing learners to become more effective autonomous learners in the future. By writing or speaking their ideas/thoughts on the net, learners are able to achieve greater ownership and personal responsibility in their language production. They may be more aware of their audience and monitor their output with greater attentional control. Accordingly, more care will likely be taken to use language that is ppragmatically and grammatically accurate, and interaction will become more meaningful than traditional classroom activities can achieve on their own. Finally, since learners can use various devices and modalities to express their thoughts and ideas on the web, it will enhance flexibility. And since teachers can have more opportunities to evaluate their students via these formats than tradition classroom instruction, they can also have more flexible and authentic means to evaluate learners.

These tools are extremely valuable and can offer a wealth of advantages to foreign language learners. They offer significant potential in blended learning environments, where classes meet both on- and off-line, or in distance learning environments, where students and teachers meet only online. One of the benefits of MALL and Web 2.0 is that anyone can meet anytime anywhere around the world. Thus, if these technologies are adopted in blended or distance foreign language learning programs, the particular efficiencies and potentials of these programs will be maximized. Instruction will better address the needs of those learners who have limited time to attend a class, but who are eager to learn a foreign language, and so can be applied to both traditional students and non-traditional learners; be they businessman, housewives, or even teachers. If used appropriately, mobile devices and Web 2.0 technologies have limitless applicability that can provide not just convenience and novelty but, far more importantly, efficacious pedagogy for the modern foreign language learner. 


\section{FUTURE RESEARCH}

The rapid development of language-related technology in general, and mobile webbased technologies in particular, has resulted in an increasing number of technologically savvy students; a phenomenon that is almost certain to accelerate in the future. Web 2.0 technologies and mobile devices offer significant advantages in that they can connect people around the world instantly and without the restrictions of time and place that normally dictate language instruction and practice. Now is an ideal time for foreign language pedagogues and curriculum designers to develop competency and facility with these tools and for teacher training programs to incorporate formal preparation in the application of such mobile technologies to the language learning classroom. At present, there is a dearth of research on such technology overall and their incorporation into instructional and teacher training contexts specifically. Given the potential offered by mobile technologies to improve not just the teaching and learning enterprise, but also the opportunities for the field to adapt to an increasingly time and resource sensitive environment for language programs, additional and comprehensive research is desperately needed in this area.

The majority of research completed to date in terms of Web 2.0 technologies have examined the use the blogs and wikis, which have quite a long history compared to other newly developed Web 2.0 tools. Thus, educators interested in these technologies can follow the previous classroom uses such as cultural projects in blogs (Ducate \& Lomicka, 2005) and collaborative writing in wikis (Kessler, 2009; Lund, 2008, for comprehensive application of wiki, see Parker \& Chao, 2007) as a first step. With regards to other emerging Web 2.0 tools and the access of such tools via mobile devices, teachers must begin innovating now and share their findings with the field at large. Indeed, this area of language technology instruction seems ripe for precisely the type of Classroom Action Research that only pedagogues in the field can provide and evaluate.

\section{CONCLUSION}

This paper examined the potential application of mobile devices in combination with Web 2.0 tools. We reviewed the definitions of key terms and connected the potential applications of these technologies with several major paradigms of second language acquisition theory: Input, interaction and feedback. We also examined and evaluated a variety of specific examples of Web 2.0 technology that can be used with mobile devices, including: Blogging, Audio blogging, Mobile blogging, Video blogging, Wikis, Facebook, Flickr and Google Maps. We then examined the pedagogical affordances of using these tools in foreign language instruction, which include increased authenticity, reduced anxiety with higher motivation, opportunities for learner-centered instruction, enhanced ownership and personal responsibility, significant flexibility in learning preferences and styles, opportunities for meaningful interaction, combining "flow" with fun, and intertwining multimodal 
input and output. Finally, we reviewed the future growth and relevance of these tools, and how they can be combined with innovative pedagogy and additional [action] research to advance this area of technology enhanced instruction for the benefit of individual learners and the field of language instruction as a whole. Certainly then, it is important for teachers to investigate and incorporate MALL with Web 2.0 in their instruction to facilitate these goals. 


\section{REFERENCES}

Benson, P. (2001). Teaching and researching autonomy in language learning. London: Longman.

Campbell, A.P. (2003). Weblogs for use with ESL classes. The Internet TESL Journal, 9(2). Retrieved from http://iteslj.org/Techniques/CampbellWeblogs.html.

Candy, P. (1991). Self-direction for lifelong learning; a comprehensive guide to theory and practice. Jossey-Bass: CA.

Csikszentmihaly, M. (1991). Flow: the psychology of optimal experience. Harper Collins: New York.

Ducate, L.C. \& Lomicka, L.L. (2005). Exploring the blogosphere: Use of web logs in the foreign language classroom. Foreign Language Annals, 38(3), 410-421.

Gass, S. (1997). Input, interaction, and the second language learner. Mahwah, NJ: Lawrence Erlbaum Associates, Publishers.

Godwin-Jones, B. (2003). Blogs and wikis: Environments for on-line collaboration. Language Learning \& Technology, 7(2), 12-16.

Holec, H. (1979). Autonomy and foreign language learning. Council for Cultural Cooperation, Strasbourg (France).

Horwitz, Horwtiz, \& Cope. (1986). Foreign language classroom anxiety. Modern Language Journal, 70 (2), 125-132.

Jee, M. J. (2008). Using Blogs as ePortfolios in ESL/EFL Writing Classes. The Newsletter of TESOL's Second Language Writing Interest Section, Volume 3 Number 2.

Kessler, G. (2009). Student-initiated attention to form in wiki-based collaborative writing. Language Learning \& Technology, 13(1), pp. 79-95.

Krashen, S. (1985). The Input Hypothesis: Issues and Implications. Laredo, Beverly Hills, CA.Kukulska-Hulme, A. \& Shield, L. (2008). An overview of mobile assisted language learning: From content delivery to supported collaboration and interaction. ReCALL, 20(3), 271-289.

Long, M. (1983). Linguistic and conversational adjustments to non-native speakers. Studies in Second Language Acquisition, 5, 177-194. 
Long, M. H. (1990). The least a second language acquisition theory needs to explain. TESOL Quarterly, 24(4), 649-666.

Long, M. H. (1996). The role of the linguistic environment in second language acquisition. In W. Ritchie \& T. Bhatia (Eds.), Handbook of second language acquisition (pp. 413-468). New York: Academic Press.

Long, M. H., Inagaki, S., \& Ortega, L. (1998). The role of implicit negative feedback in SLA: Models and recasts in Japanese and Spanish. Modern Language Journal, 82, 357-371.

Lund, A. (2008). Wikis: a collective approach to language production. ReCALL, 20, 35-54.

Murray, L. \& Hourigan, T. (2006). Using micropublishing to facilitate writing in the foreign language. In L. Ducate, \& N. Arnold (Ed.), Calling on CALL: from theory to research to new directions in foreign language teaching (pp. 149-179). Texas: CALICO Monograph series.

Parker, K. \& Chao, J. (2007). Wiki as a teaching tool. Interdisciplinary Journal of Knowledge and Learning Objects, 3.

Schwartz, L., Clark, S., Cossarin, M., \& Rudolph, J. (2004). Educational wikis: features and selection criteria. International Review of Research in Open and Distance Learning. 5(1).

Trifanova, A., Knapp, J., Ronchetti, M, \& Gamper, J. (2004). Mobile ELDIT: Challenges in the transitions from an e-learning to an m-learning system. Trento, Italy: University of Trento.

Ward, J.M. (2004). Blog Assisted Language Learning (BALL): Push button publishing for the pupils. TEFL WebJournal, 3, 1-16. Retrieved from http://www.teflweb-j.org/v3n1/blog_ward.pdf.

Warschauer, M. \& Shetzer, H. (2000). An electronic literacy approach to network-based language teaching. In. M. Warschauer \& R. Kern (Ed.), Network-based language teaching: concepts and practice (pp. 171-185). Cambridge, MA: MIT Press.

Winer, D. (2003, May 23). What makes a weblog a weblog? Weblogs at Harvard Law. Message. Retrieved May 23, 2003 from http://blogs.law.harvard.edu/whatmakesaweblogaweblog. 


\section{About The Author}

Min Jung Jee earned her Ph.D degree from the Foreign Language Education Program at the University of Texas at Austin. She had taught English in Korea and her research interests are Second Language Acquisition, Computer-Assisted Language Learning, Computer-Mediated Communication, and discourse analysis. She is currently teaching Korean at the University of Texas at Austin. 